\title{
Aspects of Therapy for Cervical Cancer in Germany 2012 - Results from a Survey of German Gynaecological Hospitals
}

\author{
Aspekte der Therapie des Zervixkarzinoms in Deutschland 2012 - \\ Ergebnisse einer Umfrage unter den deutschen Kliniken für Gynäkologie
}

Authors

Affiliations
M. Mangler ${ }^{1}$, N. Zech² ${ }^{2}$ A. Schneider ${ }^{2}$, C. Köhler ${ }^{2}$, S. Marnitz ${ }^{3}$

Gynecology, Charité, Berlin

Gynäkologie, Charité, Berlin

3 Radiotherapie, Charité, Berlin
Key words

- staging of cervical cancer

- radiochemotherapy for cervical cancer

- radical hysterectomy

- questionnaire on treatment situation

- therapeutic concepts

- stage-dependent therapy

Schlüsselwörter

- Staging bei Zervixkarzinom

- Radiochemotherapie bei

Zervixkarzinom

- radikale Hysterektomie

- Umfrage zur Behandlungssituation

- Therapiekonzepte

- stadienabhängige Therapie

\begin{abstract}
received 8.1.2013
revised 24.1.2013

accepted 1.2.2013
\end{abstract}

\section{Bibliography}

Dol http://dx.doi.org/ 10.1055/s-0032-1328302

Geburtsh Frauenheilk 2013; 73:

227-238 @ Georg Thieme

Verlag KG Stuttgart · New York ISSN 0016-5751

\section{Correspondence}

Dr. Mandy Mangler, MD

Charité

Gynecology

Charitéplatz 1

10117 Berlin

mandy.mangler@charite.de

\section{Abstract}

$\nabla$

Introduction: In spite of the existence of guidelines and international recommendations, many aspects in the diagnosis, therapy and follow-up of patients with cervical cancer are not based on validated data. A broad spectrum of different opinions and procedures concerning the therapy for patients with cervical cancer is under controversial discussion by the responsible gynaecologists in German hospitals.

Methods: The present study is intended to picture the current treatment situation for cervical cancer in Germany. For this purpose a specially developed questionnaire with questions divided into 19 subsections was sent to all 688 gynaecological hospitals in Germany.

Results: The response rate to the questionnaire was $34 \% .91 \%$ of the hospitals treated between 0 and 25 patients with cervical cancer per year. $7.5 \%$ treated between 26 and 50 and $1.4 \%$ of the hospitals more than 50 patients per year. The bimanual examination was the most frequently used staging method (98\%); PET-CT was the least used staging method (2.3\%). Interestingly $48 \%$ of the hospitals used surgical staging. The great majority of the hospitals (71\%) used abdominal radical hysterectomy (Wertheim-Meigs operation) to treat their patients. TMMR via laparotomy was used by $13 \% .16 \%$ of the hospitals performed laparoscopic or robot-assisted radical hysterectomies. The sentinel concept was hardly used even in the early stages. It must be emphasised that in $74 \%$ of the hospitals radical hysterectomies were performed even in cases with positive pelvic lymph nodes and in $43 \%$ also in cases with positive paraaortic lymph nodes. The therapy of choice for FIGO IIB cancers is primary radiochemotherapy (RCTX) in $21 \%$ of the hospitals; operative staging followed by radiochemotherapy in $24 \%$ and treatment by radical hysterectomy followed by adjuvant RCTX was employed in this sit-

\section{Zusammenfassung \\ $\nabla$}

Einleitung: Trotz der vorhandenen Leitlinien und internationalen Empfehlungen fußen viele Aspekte der Diagnostik, Therapie und der Nachsorge von Patientinnen mit Zervixkarzinomen nicht auf validen Daten. Von den behandelnden Gynäkologen in den deutschen Kliniken wird ein breites Spektrum an verschiedenen Meinungen und Herangehensweisen an die Therapie der Zervixkarzinompatientinnen kontrovers diskutiert.

Methoden: Die vorliegende Studie sollte die derzeitige Behandlungssituation des Zervixkarzinoms in Deutschland abbilden. Dazu wurde ein speziell dafür entwickelter Fragebogen, der Fragen zu 19 Teilbereichen abdeckte, an alle 688 deutschen Kliniken für Gynäkologie versandt. Resultate: Die Rücklaufrate der Fragebögen war 34\%. 91\% der Kliniken behandelten zwischen 0 und 25 Patientinnen mit Zervixkarzinomen pro Jahr. 7,5\% zwischen 26 und 50 und 1,4\% der Kliniken mehr als 50 Patientinnen/Jahr. Die bimanuelle Untersuchung war die am häufigsten eingesetzte Stagingmethode (98\%), das PET-CT wurde zum Staging am seltensten beansprucht (2,3\%). Interessanterweise setzten $48 \%$ der Kliniken ein operatives Staging um. Die große Mehrheit der Kliniken $(71 \%)$ therapierte die Patientinnen per abdominaler radikaler Hysterektomie (Wertheim-Meigs-Operation). Die TMMR per Laparotomie wurde von 13\% eingesetzt, 16\% der Kliniken operierten laparoskopisch oder roboterassoziiert per radikaler Hysterektomie. Das Sentinel-Konzept wurde auch bei Frühstadien kaum verwandt. Hervorzuheben ist, dass in 74\% der Kliniken radikale Hysterektomien auch bei positiven pelvinen Lymphknoten und in $43 \%$ auch bei positiven paraaortalen Lymphknoten durchgeführt wurden. Die Therapie der Wahl bei FIGO-IIB-Karzinomen war die primäre Radiochemotherapie (RCTX) in 21\% der Kliniken, ein operatives Staging gefolgt von einer Radiochemotherapie in $24 \%$ und 
uation by $46 \%$ of the hospitals. In $15-97 \%$ of the hospitals for node-negative and in sano resected patients in stage pT1B1/1B2 after radical hysterectomy, an adjuvant RCTX is recommended when further risk factors exist (LVSI, tumour $>4 \mathrm{~cm}$, age $<40$ years, adenocarcinoma, S3).

Conclusion: A broad spectrum of differing staging and therapy concepts is in use for patients with cervical cancer in Germany. A standardisation of therapy is needed. An update of national guidelines could help to achieve more transparency and a standardisation of treatment for patients with cervical cancer.

\begin{tabular}{ll}
\hline Abbreviations \\
FIGO & $\begin{array}{l}\text { Fédération Internationale de Gynécologie } \\
\text { et d'Obstétrique }\end{array}$ \\
GOG & $\begin{array}{l}\text { Gynecologic Oncology Group } \\
\text { NCCN }\end{array}$ \\
National Comprehensive Cancer Network \\
PFS & Overall survival \\
RCTX & Progression-free survival \\
RH & Radiochemotherapy \\
TMMR & Radical hysterectomy \\
VALRH & Vaginal-assisted laparoscopic radical hysterectomy \\
LARVH & laparoscopic assisted radical vaginal hysterectomy
\end{tabular}

\section{Introduction}

$\nabla$

The treatment of patients with invasive cervical cancer in Germany should be oriented on the currently valid AGO guidelines [1]. These guidelines, as well as international recommendations (e.g., NCCN) are based on prospective and retrospective monoand multicentric data, since only few prospective randomised studies are available [2]. Even for the radical hysterectomy ( $\mathrm{RH})$ which has been practiced for more than one hundred years there are today still no randomised studies comparing the various surgical techniques [99]. Also the classification of radicality by various groups has not led to a standardisation of the surgical methods $[3,4]$. In addition, because of the declining incidence of invasive cervical cancer - with 4880 newly diagnosed cases and 1600 deaths in Germany, fewer and fewer patients per hospital are being treated which will lead to appreciable problems with regard to experience and training [5].

On the other hand novel diagnostic [100], surgical and radiooncological procedures are being introduced and need to be evaluated [101]. The staging system for cervical cancer according to FIGO is today based solely on gynaecological examinations and cystoscopy/rectoscopy. Although MRI and CT have clear limitations for the staging of women with cervical cancer they are being employed more and more [6]. Whether or not PET-CT can provide improved data for staging is currently not clear [7-10]. Also the oncological relevance of surgical staging is still being discussed controversially and is being checked in the Uterus-11 study of AGO [11-13]. The sentinel concept appears to be applicable with high sensitivity and detection rates for tumours $<2 \mathrm{~cm}$; even so there are reservations due to the low prevalence of positive lymph nodes in cases of tumours in stages IA1-IB1 [14,15]. Beside the classical abdominal $\mathrm{RH}$, in recent years other procedures such die Behandlung per radikaler Hysterektomie gefolgt von adjuvanter RCTX wurde in dieser Situation von $46 \%$ der Kliniken umgesetzt. In 15-97\% der Kliniken wurde bei nodalnegativen und in sano resezierten Patientinnen nach radikaler Hysterektomie im Stadium pT1B1/1B2 eine adjuvante RCTX empfohlen, wenn weitere Risikofaktoren auftraten (LVSI, Tumor $>4 \mathrm{~cm}$, Alter $<40$ Jahre, Adenokarzinome, G3).

Zusammenfassung: Ein breites Spektrum an verschiedenen Staging- und Therapiekonzepten bei Patientinnen mit Zervixkarzinom wird in Deutschland eingesetzt. Es bedarf einer Standardisierung der Therapie. Ein Update der nationalen Leitlinien kann helfen, mehr Klarheit und eine Standardisierung in die Behandlung von Patientinnen mit Zervixkarzinom zu bringen.

as total laparoscopic RH [16-20], laparoscope-assisted radical vaginal RH [21-24] or vaginal-assisted laparoscopic RH [25], robot-assisted RH [26-28] and TMMR [29] have been developed and provided highly promising oncological results. Nerve-sparing operations also help to markedly reduce the postoperative morbidity. Also from the radiotherapy side, considerable improvements in the treatment of patients with cervical cancer have been achieved. Beside the usual combination of chemotherapy and radiation (radiochemotherapy = RCTX), which achieves a significant improvement in survival for the patient [30-34], it is above all the use of innovative techniques of radiation that clearly reduces the rate of side effects caused by the therapy $[35,36]$. The sole randomised study to compare radical hysterectomy with radiotherapy alone by Landoni in 1997 must now be considered as outdated with regard to the radiotherapy-associated side effects [37]. Also in the most recent publications on $\mathrm{RH}$ more than $50 \%$ of the patients receive a postoperative adjuvant radiochemotherapy, which is often associated with an increased morbidity $[38,39]$. The criteria for an adjuvant therapy are applied in widely different ways in spite of the GOG-109 data [40-43]. Furthermore, different algorithms are used in the follow-up [44-46].

The large number of open and controversial topics prompted our group to develop a questionnaire to assess the current status in the treatment of women with cervical cancer, even though we do not make any claims to completeness for this compilation.

\section{Material and Methods \\ $\nabla$}

Between February 2012 and June 2012 a questionnaire comprising 19 topic complexes was sent to the heads of all gynaecological hospitals nationwide in Germany (Questionnaire - 0 Fig. 1). The data were evaluated using SPSS. Percentage values each refer to the number of usable replies to the particular topic.

\section{Results \\ $\boldsymbol{\nabla}$}

\section{General}

From 688 hospitals to which the questionnaire was sent 234 (34\%) answered, of these 26 were university hospitals (11\%), 113 were medical centres (49\%) and 93 were regional and general hospitals ( $40 \%) .28 \%(n=63)$ of these hospitals are certified as centres for gynaecological oncology. All hospitals were subdivided into 3 groups according to the number of patients with cervical cancer treated per year: 1: 0-25 patients, 2: 26-50, 3: more than 50 . The university hospitals could be assigned as fol- 


\section{Questionnaire on therapy for cervical cancer 2012}

Achim Schneider and Christhardt Köhler - Klinik für Gynäkologie, Charité Berlin Simone Marnitz, Klinik für Strahlentherapie, Charité Berlin

(It should not take more than 15 minutes to answer all questions; solely question 13 is somewhat more extensive but concerns an extremely important and controversially discussed topic.)

\section{General}

1. What type of hospital do you work in?
$\square$ University hospital
Medical centre/specialist hospital
$\square$ General regional hospital

2. Is your department certified as a centre for gynaecological oncology?
$\square$ Yes
$\square$ No

3. How many patients with invasive cervical cancer of the following FIGO stages did you treat last year (2011)?

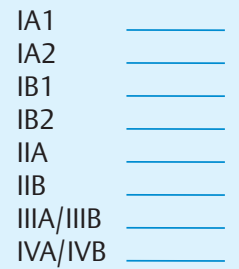

Have the answers to this question been taken from a register or are they estimated?

\section{Staging}

4. Which imaging/staging examinations do you usually perform from stage IB1 (please check - multiple answers are possible)?

$\square$ Bimanual exam
$\square$ Cystoscopy
$\square$ Rectoscopy
$\square$ CT
$\square$ MRI
$\square$ PET-CT
$\square$ Surgical staging

5. If you regularly perform surgical staging which operative approach do you use in the majority of cases (please name only one procedure)?
$\square$ Open transperitoneal
$\square$ Open retroperitoneal
$\square$ Laparoscopic transperitoneal
$\square$ Laparoscopic extraperitoneal
$\square$ Robot-assisted transperitoneal
$\square$ Robot-assisted retroperitoneal

6. Do you perform sentinel lymph node procedures in women with cervical cancer (please give only one answer)?

$\square$ In all stages routinely

$\square$ Only for tumours $<2 \mathrm{~cm}$, but then for all patients

$\square$ Only within studies

$\square$ Only if requested by the patient

\section{Surgical therapy}

7. Which type of radical hysterectomy do you perform mainly? Please check only one or two boxes, if two please give percentages for each of the two methods.

$\square$ Classic Wertheim operation (open surgery)

$\square$ TMMR (open surgery)

$\square$ Laparoscopic-assisted radical vaginal (LARVH) or vaginal-assisted laparoscopic radical hysterectomy (VALRH)

$\square$ Total laparoscopic radical hysterectomy (TLRH)

$\square$ Robot-assisted radical hysterectomy (RRH)

$\square$ Robot-assisted TMMR

Others (please name them)

8. Do you as a general rule perform an intraoperative immediate section for microscopy of the resected lymph nodes (please check only one box)?

$\square$ Yes

$\square$ No

$\square$ Only for suspicious enlargement of individual lymph nodes

$\square$ As a rule two-stage procedure (1st OP lymphonodectomy, radical hysterectomy as 2 nd OP only when free of tumour)

9. What is your usual procedure for positive pelvic lymph nodes in cases of operable local tumours (please check only one box)?

$\square$ Discontinue the radical HE, paraaortal lymphonodectomy and primary radiochemotherapy (RCTX)

$\square$ Continue the radical HE, paraaortal lymphonodectomy and adjuvant RCTX

$\square$ Continue the radical HE, paraaortal lymphonodectomy and adjuvant chemotherapy

10. What is your usual procedure for positive paraaortic lymph nodes in cases of operable local tumours (please check only one box)?

$\square$ Discontinue the radical HE and primary radiochemotherapy, including the paraaortic region (extended field)

$\square$ Discontinue the radical HE and palliative chemotherapy

$\square$ Continue the radical $\mathrm{HE}$ and adjuvant radiochemotherapy

$\square$ Continue the radical HE and adjuvant chemotherapy

\section{Stage-specific questions}

11. In stage IA1 L0 do you perform a sentinel lymphonodectomy in addition to re-conisation/simple hysterectomy?
$\square$ Yes
$\square$ No

Fig. 1 Questionnaire. (continued next page) 
12. For a patient with cervical cancer in stage $\mathrm{IB} 1<2 \mathrm{~cm}$ who still wants to have a child, do you (please check only one box)...

$\square$... always perform a radical HE because you do not approve of trachelectomy.

$\square$... refer the patient to a centre experienced in trachelectomy.

$\square$....always perform a radical trachelectomy.

If yes: $\quad \square$ As a radical vaginal trachelectomy

$\square$ As a radical abdominal trachelectomy

$\square$ As a robot-assisted radical trachelectomy

13. When do you, as surgeon, recommend adjuvant radiochemotherapy after radical hysterectomy in stages IB1/IB2 (multiple answers possible):

For positive nodes; $\mathrm{R} 1 / \mathrm{R} 2$ resection and/or tumour invasion of the parametrium

If NO, RO and stage pT1b1 or pT1B2, do you recommend adjuvant RCT in the presence of the following risk factors (please check as appropriate):

Only grade 3 (G3)

Only tumour size $>4 \mathrm{~cm}$

Only age $<40$ years

Only by invasion of the lymphovascular space

(L1)

Only adenocarcinoma as histological type

For 2 risk factors:

Combination $\mathrm{G} 3+$ age $<40$

Combination $\mathrm{G} 3+$ tumour $>4 \mathrm{~cm}$

Combination $\mathrm{G} 3+\mathrm{L} 1$

Combination G3 and adenocarcinoma

Combination tumour $>4 \mathrm{~cm}$ and age $<40$

Combination tumour $>4 \mathrm{~cm}$ and $\mathrm{L} 1$

Combination tumour $>4 \mathrm{~cm}$ and adenocarcinoma

Combination age $<40$ and $\mathrm{L} 1$

Combination age $<40$ and adenocarcinoma

Combination L1 and adenocarcinoma

For 3 risk factors:

Combination $\mathrm{G} 3+$ tumour $>4 \mathrm{~cm}+$ age $<40$

Combination $\mathrm{G} 3+$ tumour $>4 \mathrm{~cm}+\mathrm{L} 1$

Combination $\mathrm{G} 3+$ tumour $>4 \mathrm{~cm}+$ adenocarcinoma

Combination $\mathrm{G} 3+$ age $<40+\mathrm{L} 1$

Combination $\mathrm{G} 3+$ age $<40+$ adenocarcinoma

Combination $\mathrm{G} 3+\mathrm{L} 1$ + adenocarcinoma

Combination tumour $>4 \mathrm{~cm}+$ age $<40+\mathrm{L} 1$

Combination tumour $>4 \mathrm{~cm}+$ age $<40+$ adenocarcinoma

Combination tumour $>4 \mathrm{~cm}+\mathrm{L} 1+$ adenocarcinoma

Combination age $<40+\mathrm{L} 1+$ adenocarcinoma

For 4 risk factors:

Combination $\mathrm{G} 3+$ tumour $>4 \mathrm{~cm}+$ age $<40+\mathrm{L} 1$

Combination $\mathrm{G} 3+$ tumour $>4 \mathrm{~cm}+$ age $<40+$ adenocarcinoma

Combination $\mathrm{G} 3+$ tumour $>4 \mathrm{~cm}+\mathrm{L} 1+$ adenocarcinoma

Combination tumour $>4 \mathrm{~cm}+$ age $<40+$

L1 + adenocarcinoma

Combination $\mathrm{G} 3+$ age $<40+$

adenocarcinoma $+\mathrm{L} 1$
14. Do you as a general rule initiate a neoadjuvant therapy in stage IB2 or IIB prior to a planned radical hysterectomy (please check only one box)?

$\square$ Yes, a neoadjuvant chemotherapy

$\square$ Yes, a neoadjuvant radiochemotherapy

$\square$ No

$\square$ I always refer theses stages to primary radiochemotherapy.

15. What is your therapy for the majority of patients in FIGO stage IIB (please check only one box)?

$\square$ Primary radiochemotherapy

$\square$ Surgical staging and subsequent primary radiochemotherapy

$\square$ Radial hysterectomy and adjuvant radiochemotherapy

$\square$ Others (please specify)

16. Which type of staging do you perform in FIGO stages IIIA/IIIB?

$\square$ Clinical staging before radiochemotherapy

$\square$ Surgical staging before radiochemotherapy

17. What is your therapy in stage IVA (multiple answers possible)?

Always primary radiochemotherapy

Always primary exenteration

$\square$ Primary exenteration only for urogenital or intestinogenital fistula

$\square$ Individual decision

\section{Postoperative decisions/follow-up}

18. What examinations do you perform on patients after primary radiochemotherapy (without prior radical hysterectomy) in the follow-up period (multiple answers possible)?

Clinical examination

Renal ultrasonography

Vaginal ultrasonography

Determination of tumour markers

Pelvic MRI

PET-CT

Cervix abrasion

PAP smear

19. In your opinion when is an operation indicated after primary radiochemotherapy (without radical hysterectomy) (please check only one box)?

$\square$ There is no indication because there is no advantage in survival.

$\square$ Secondary hysterectomy is always performed.

$\square$ A secondary hysterectomy is performed only on suspicion of a persisting tumour (e.g. in the abrasion).

$\square$ On suspicion of a local recurrence a secondary exenteration is always performed.

Fig. 1 Questionnaire. (continued) 


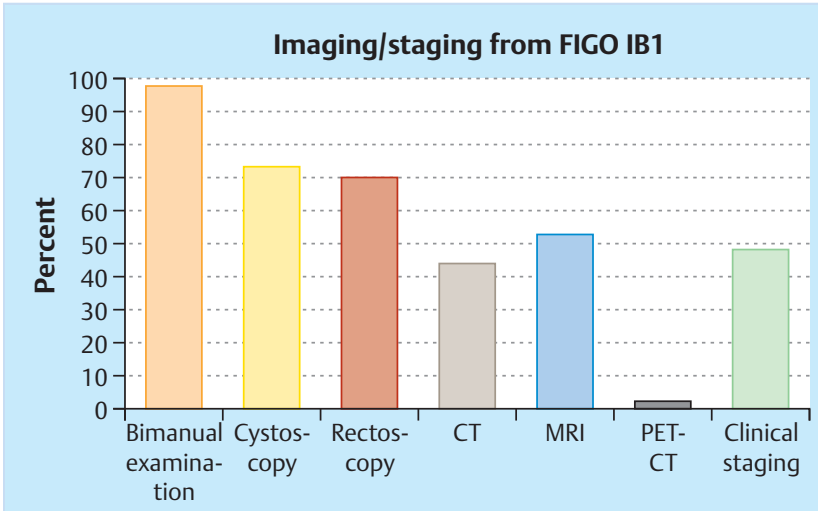

Fig. 2 Applied staging examinations from FIGO IB1 (multiple answers possible).

lows to the groups 1, 2 and 3, respectively, 14 (61\%), 6 (26\%) and 3 (13\%). Three university hospitals did not give an answer to the number of treated patients per year. For medical centres and regional/general hospitals the assignments were as follows: $1=94 \%, 2=6 \%, 3=0 \%$ and, respectively, $1=95.5 \%, 2=4.5 \%$ and $3=00 \%$. Altogether $91 \%$ of all patients with cervical cancer were treated in a hospital that handles less than 26 such patients per year.

\section{Staging}

In practically all hospitals, staging from stage IB1 was done according to FIGO by bimanual examination (98\%). Cystoscopy and rectoscopy were done in $73 \%$ and, respectively, $70 \%$ of the gynaecological departments. $44 \%$ of the hospitals used CT routinely, $52 \%$ used MRI, whereas in only $2 \%$ PET-CT was used for staging ( Fig. 2). Surgical staging was preferred in $48 \%$ of the responding hospitals. Here the following approaches for surgical staging were used: open transperitoneal in $41 \%$, open retroperitoneal in $9 \%$, laparoscopic transperitoneal in $47 \%$, laparoscopic extraperitoneal in $1 \%$ and robot-assisted transperitoneal in $2 \%$. The sentinel concept was not utilised in $43 \%$; $9 \%$ of the hospitals performed sentinel lymphonodectomy in all patients with tumours $\leq 2 \mathrm{~cm}, 22 \%$ only within studies and $22 \%$ only if requested by the patient. In 9 gynaecological departments (4\%) the sentinel concept is applied to all tumour stages ( Fig. 3). Almost all hospitals

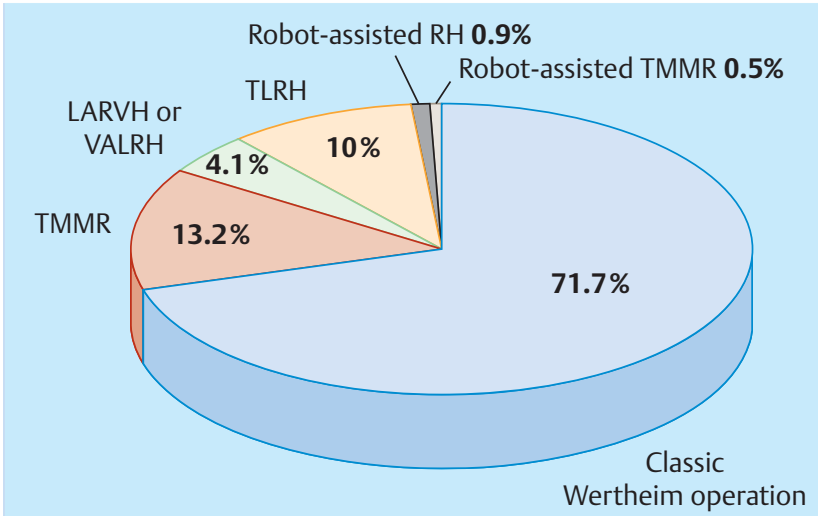

Fig. 4 Methods for radical hysterectomy that were used predominantly in the department.

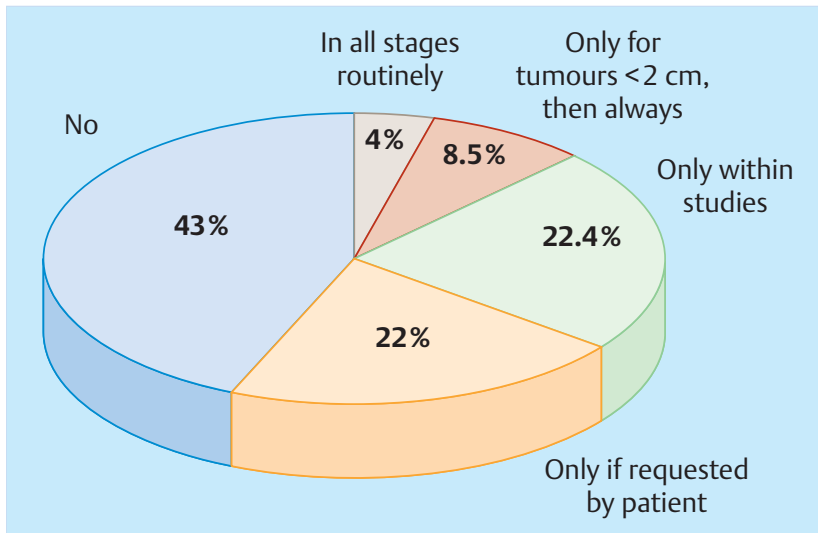

Fig. 3 Use of the sentinel concept in patients with cervical cancer.

(96\%) reject the sentinel concept as an addition to conisation/ simple hysterectomy for patients with a cervical cancer stage pTla1.

\section{Therapy}

In the great majority of the gynaecological hospitals in Germany the classic open Wertheim operation is used (71.5\%). Other procedures for RH with markedly lower usage are represented by laparoscopic-assisted vaginal or vaginal-assisted laparoscopic $\mathrm{RH}$ in $4 \%$, total laparoscopic RH in 10\%, TMMR in $13 \%$, robot-assisted RH in $1 \%$ and robot-assisted TMMR in $0.5 \%$. In $32 \%$ of the hospitals several procedures were regularly applied ( $\bullet$ Fig. 4). An intraoperative immediate section of all resected lymph nodes is offered in $57 \%$ of the hospitals, in $26 \%$ only for suspiciously enlarged lymph nodes. In $2 \%$ of the hospitals - in the sense of a two-stage procedure - a lymphonodectomy is performed first followed by RH only after confirmation of tumour-free lymph nodes (๑ Fig. 5).

In the cases with the identification of positive pelvic lymph nodes in patients with a local operable tumour the $\mathrm{RH}$ is discontinued in $16 \%$ of the hospitals and, after performance of a paraaortic lymphonodectomy, a primary radiochemotherapy is initiated. $74 \%$ of the physicians continue the RH (including a paraaortic lymphonodectomy) and recommend adjuvant RCTX or adjuvant chemotherapy (10\%) (ه Fig. 6). Upon identification of positive

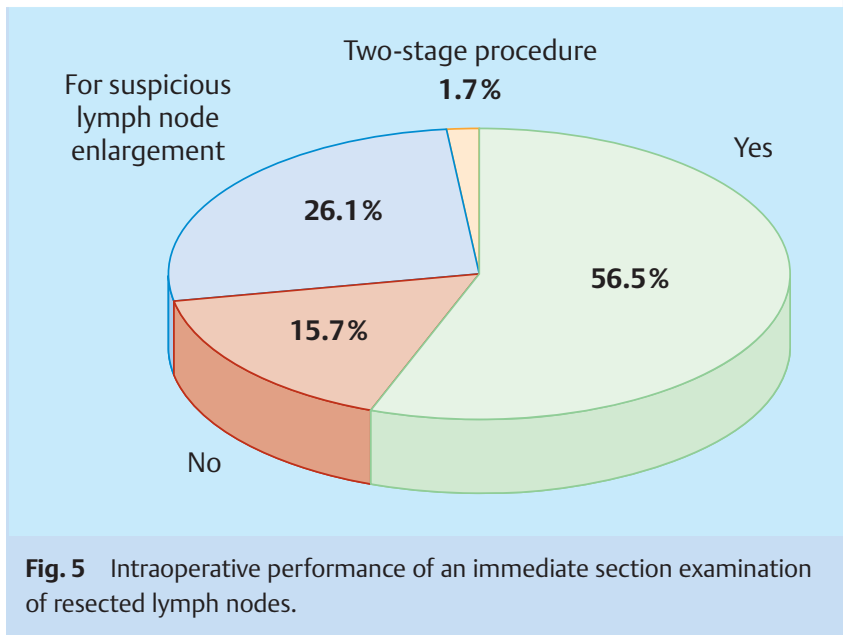



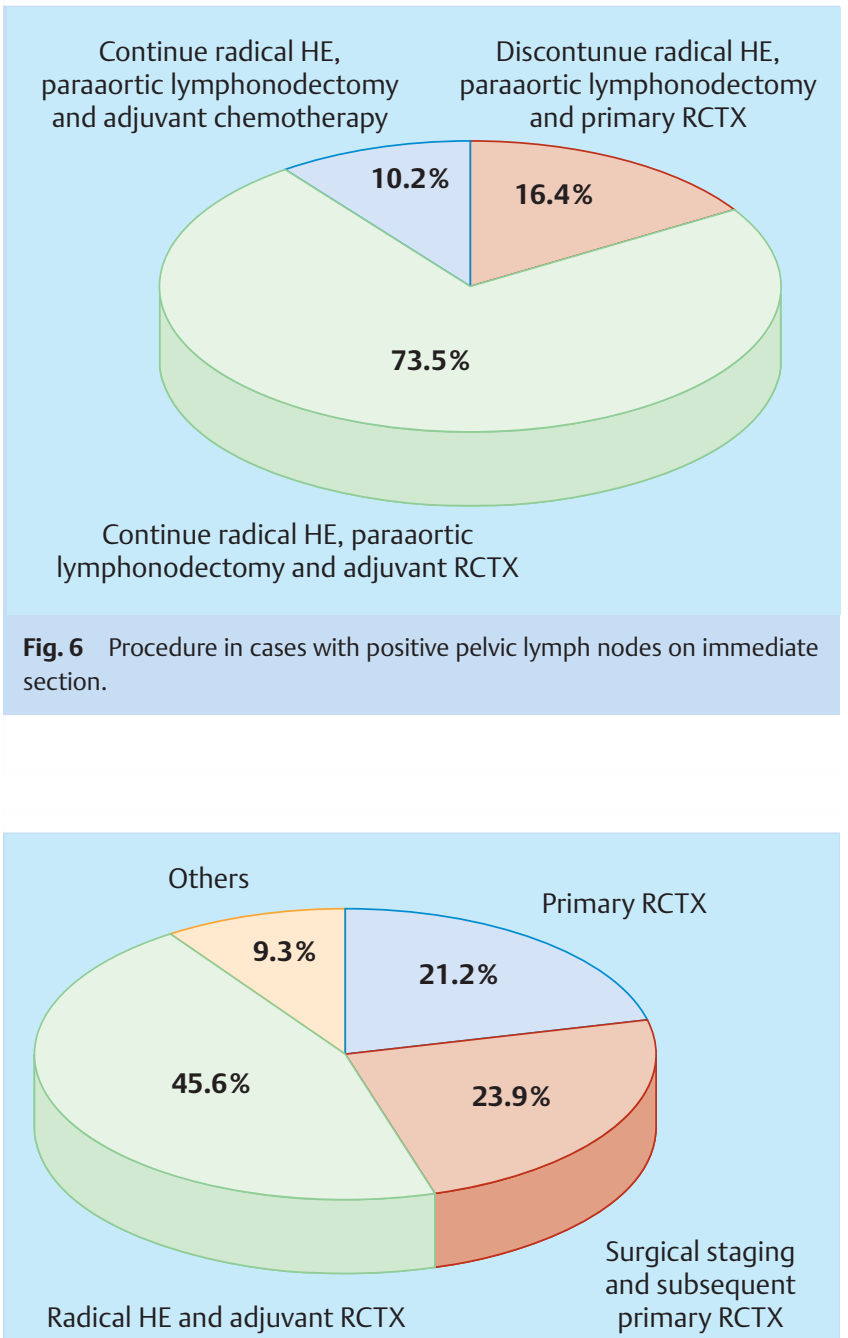

Fig. 8 Preferred therapy for FIGO stage IIB.

paraaortic lymph nodes of a locally operable cervical carcinoma, the operation is terminated in $50 \%$ of the patients. In $43 \%$ the $\mathrm{RH}$ is continued in this clinical situation and an adjuvant RCTX is subsequently carried out, in 7\% adjuvant chemotherapy (๑ Fig. 7). Young patients with a still unfulfilled desire to have children and a cervical cancer of less than $2 \mathrm{~cm}$ in size are referred in $80 \%$ to a centre with expertise in radical trachelectomy. $17 \%$ of the hospitals perform uterus-sparing operations in house, usually as a radical vaginal trachelectomy (14\%). Three percent of the gynaecological departments reject a trachelectomy and always prefer a $\mathrm{RH}$ for this constellation.

In FIGO stage IB2 neoadjuvant chemotherapy is applied in $6 \%$ of the clinics prior to the planned $\mathrm{RH}$ and in $10 \%$ a neoadjuvant RCTX, whereas in $75 \%$ the $\mathrm{RH}$ is performed as primary procedure. $9 \%$ of the hospitals refer patients in this stage to a primary RCTX. Also in FIGO stage IIB a primary RH followed by adjuvant RCTX is preferred by the majority of German hospitals (46\%), primary RCTX without and with laparoscopic staging in $21 \%$ and $24 \%$, respectively. More extensive therapeutic options are employed in $9 \%$ of the hospitals ( Fig. 8). For patients in stage IIIA/IIIB most physicians consider a clinical staging to be sufficient prior to a primary RCTX (69\%), merely $31 \%$ vote for a surgical staging be-
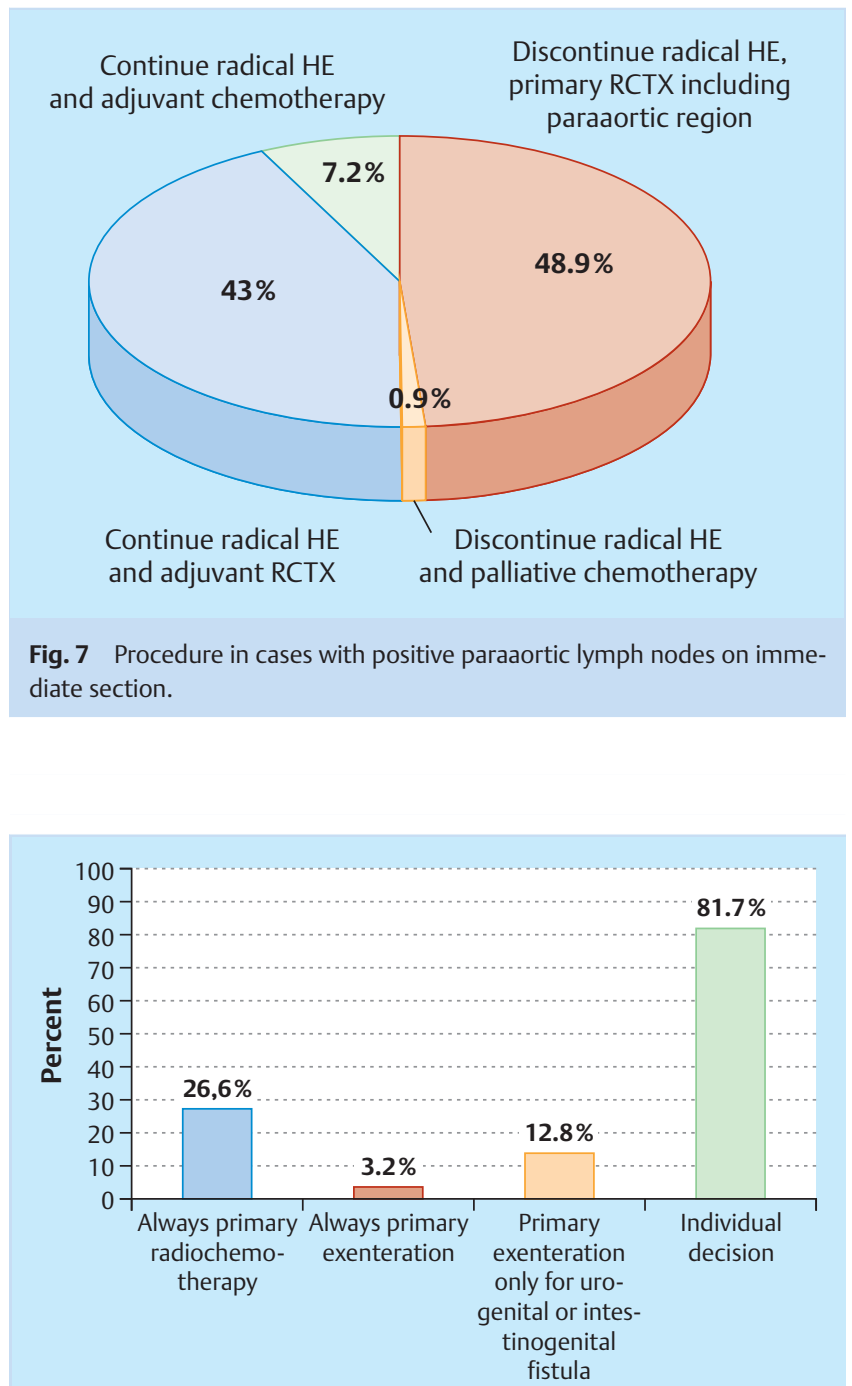

Fig. 9 Primary therapy in stage IVA (multiple answers possible).

fore commencing therapy. In stage IVA of cervical cancer individual decisions are preferred in most hospitals ( 0 Fig. 9).

The indications for adjuvant RCTX after RH form a very heterogeneous pattern. Whereas all hospitals (100\%) favour an adjuvant therapy in cases with positive lymph nodes, invasion of the

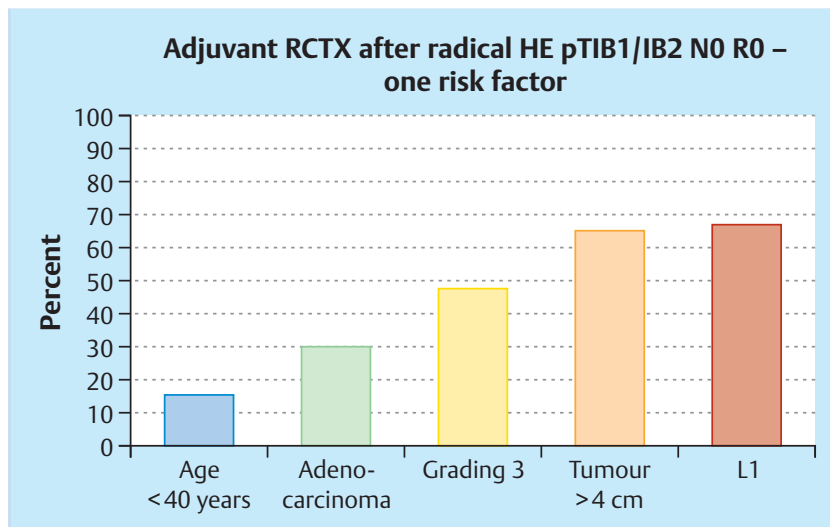

Fig. 10 Indications for adjuvant RCTX with one intermediate risk factor. 

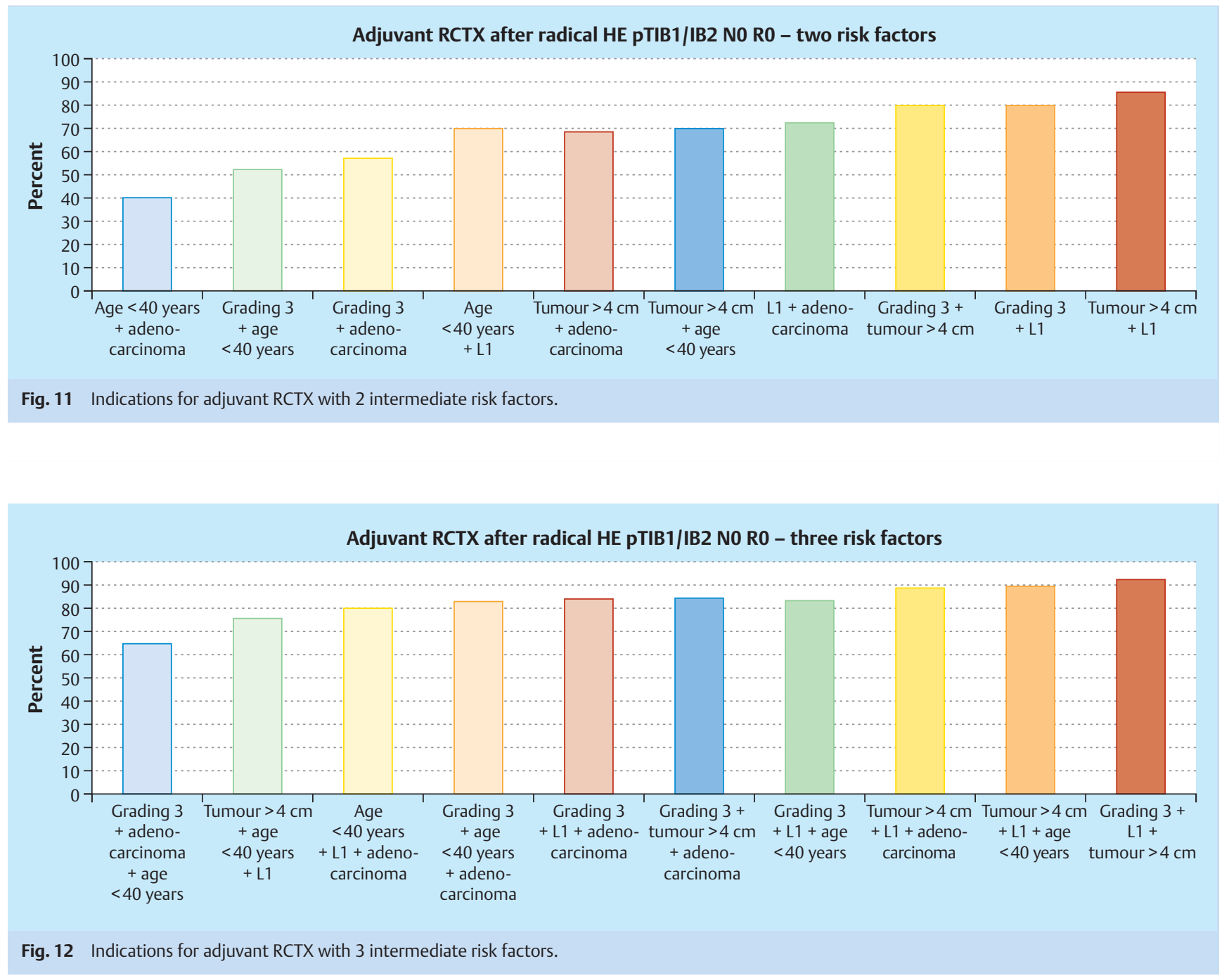

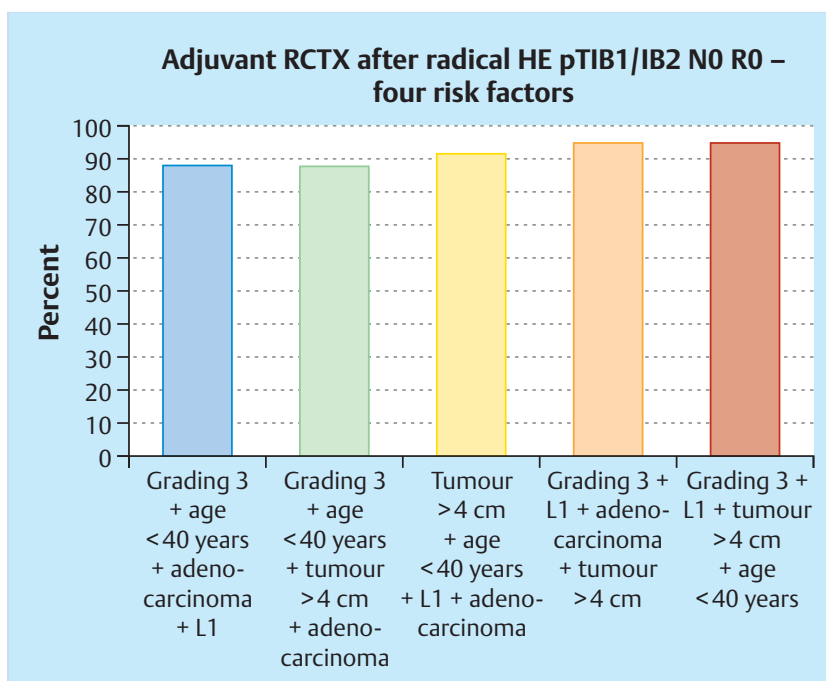

Fig. 13 Indications for adjuvant RCTX with 4 intermediate risk factors. parametrium and an $\mathrm{R} 1 / \mathrm{R} 2$ resection, the presence of the risk factors stage 3 , tumour size $>4 \mathrm{~cm}$, age $<40$ years, adenocarcinoma as histological type and invasion of the lymphovascular space (L1) alone or in combination is considered in widely differing ways ( Fig. 10 to 13). In the case of one of the above-mentioned risk factors $15-68 \%$ of the hospitals recommend an adjuvant RCTX, in the case of 2 factors $42-88 \%$, for 3 factors $68-97 \%$ and for 4 factors $90-97 \%$.

\section{Follow-up}

In the course of follow-up after primary radiochemotherapy in practically all hospitals a gynaecological examination (99\%) and vaginal ultrasonography (99\%) are performed. In $90 \%$ of the hospitals in addition ultrasonography of the kidneys is performed, a PAP smear in $75 \%$, a cervical abrasion in $28 \%$, a pelvic MRI in $41 \%$, a tumour marker determination in $28 \%$ and/or a PET-CT in $4 \%$ ( Fig. 14). On identification of a local persisting tumour/intrauterine recurrence after primary radiochemotherapy only $28 \%$ of the hospitals consider a secondary hysterectomy as not being indicated, since it is not associated with a benefit in terms of survival. In contrast $7 \%$ of the hospitals always perform a secondary hysterectomy, $57 \%$ do so only when tumour persistence is detected. Eight percent consider a primary exenteration to be indicated in this clinical situation ( $\bullet$ Fig. 15). 


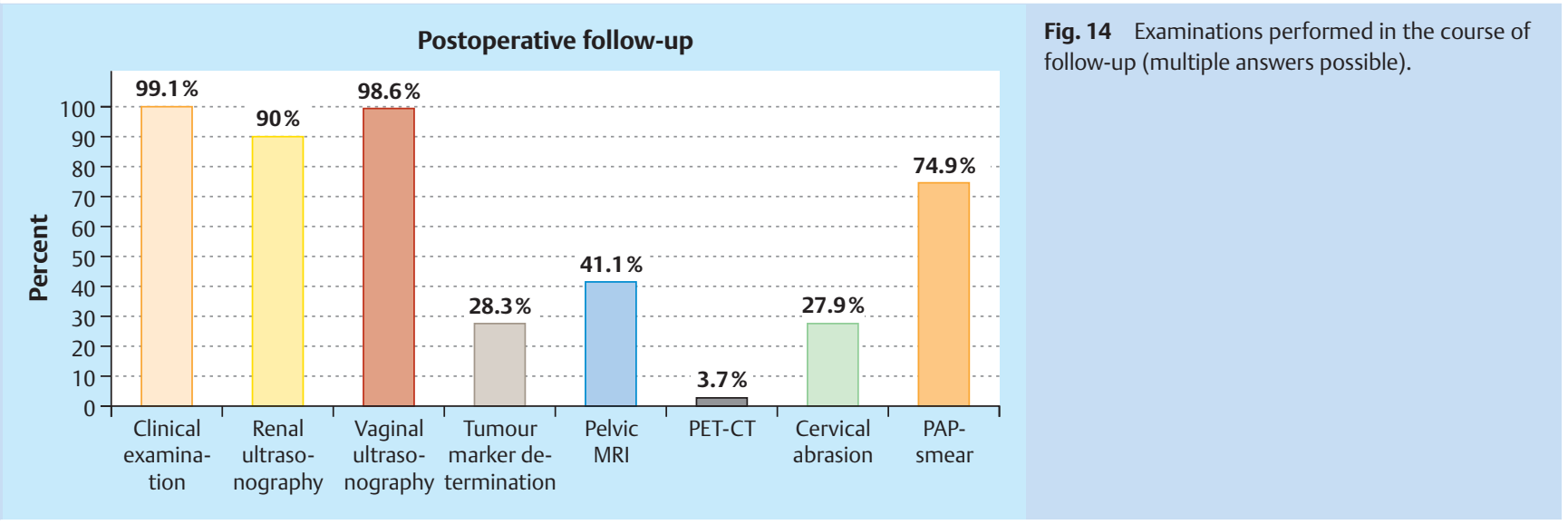

Secondary exenteration for suspected local recurrence

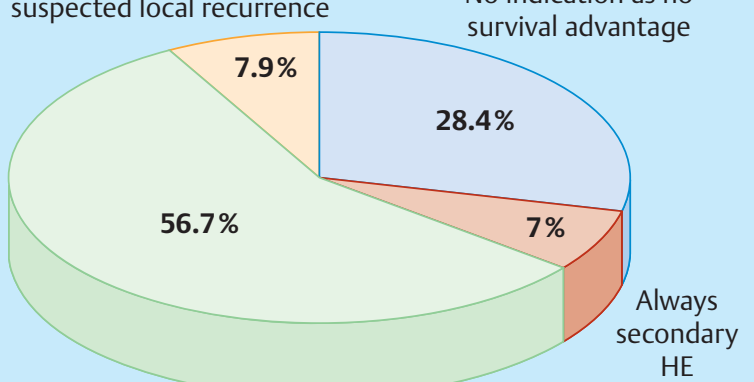

Secondary HE only for suspected persisting tumour

Fig. 15 Indication for a secondary operation after primary radiochemotherapy for cervical cancer.

\section{Discussion}

To what extent national guidelines are applied in the therapy for cervical cancer can only be determined on the basis of characteristic reimbursement data or with the help of questionnaires [47, 48]. Whereas the former is only meaningful when a separate character can be coded for every possible treatment modality, the latter is dependent on a high participation. The response rate of $34 \%$ achieved with the present questionnaire is adequate and also allows representative conclusions on the composition of the hospitals. The fact that within just a few years $28 \%$ of all hospitals have attained certification as oncological centres is indicative of an increased awareness of quality in the treatment of patients with gynaecological cancers. In spite of the gratifying decline in the incidence of these cancers, the number of patients with cervical cancer treated per hospital must be considered very critically. The numbers correspond to those gathered by Ackermann et al. in 2005 [98]. Only 19 hospitals of those that replied to our questionnaire treat more than 25 patients per year when thereby all stages IA1 to IVA are collected together. If this is extrapolated to all hospitals in Germany, at most 1000 patients are treated in hospitals with extensive expertise and only very few in high-volume hospitals. The great majority of women are treated in hospitals with low case numbers which, in turn, will lead to increasing problems in further training and the establishment of modern therapeutic concepts. The centralisation of therapy for patients with invasive cervical cancer should be a target for the future.
In 2006 the FIGO committee again decided to leave the staging of cervical cancer as a purely clinical process [49]. All German hospitals confer but only in $70 \%$ are the cystoscopic and rectoscopic examinations required by FIGO actually carried out. The routine use of CT and MRI in 44\% and 52\% reflect the widely differing data with regard to the sensitivity and specificity of these two imaging procedures found in the literature [50-54]. PET-CT, the costs of which are not reimbursed in Germany, is of no significance as a staging method in correspondence with its low sensitivity according to Ramirez et al. and LeBlanc et al. [7,8,10,55]. $48 \%$ of the hospitals consider surgical staging to be a valid alternative to imaging and to clinical staging, although as yet no randomised clinical trial has been able to confirm the oncological advantages seen in retro- and prospective studies [56,57]. The successfully recruiting prospective randomised Uterus- 11 study of AGO on the value of surgical staging in patients with cervical cancers of stages IIB-IVA should provide pathbreaking answers to this matter. Why $41 \%$ of the hospitals would still choose an open transperitoneal approach for surgical staging is not clear, since it is just the formation of postoperative adhesions before an RCTX that is the main argument against surgical staging.

The significance of the sentinel concept in cervical cancer is evaluated very differently nationwide in Germany. The results of the Uterus-3 trial of AGO published by Altgassen et al. still represent the largest investigation of this topic worldwide. These results are suggestive that SLN can achieve a sufficiently high detection and sensitivity in patients with a tumour size $<2 \mathrm{~cm}[14,58]$. Merely $9 \%$ of all hospitals in Germany employ the sentinel concept routinely for carcinomas $<2 \mathrm{~cm}$. $44 \%$ of the hospitals would apply the concept if requested by the patient or in clinical trials. The international trend to define patient collectives who would benefit from less radical surgery with equal oncological efficacy is only implemented in a few hospitals [59]. In addition, the advantages associated with the SLN technique such as the discovery of rare lymph drainage pathways [60] or the detection of micrometastasis [61] are not exploited. Lymph node metastasis in stage IA1 is rare $[15,62]$. This supports the opinion of the majority of hospitals in Germany not to use SLN in this stage. It is, however, possible that by this means one could identify with minimal morbidity just those few patients with early lymph node metastasis, whose prognosis is otherwise rather poor [63-65].

The uterus-sparing operation in cases of early invasive cervical cancer is accepted in $97 \%$ of the gynaecological departments on account of its excellent oncological and reproductive results [66-68]. In Germany this is almost exclusively performed as rad- 
ical vaginal trachelectomy in contrast to other countries where abdominal radical trachelectomy also has a high relevance [47]. Various procedures are in use in Germany for radical hysterectomy, in some cases even in one hospital. A positive development is that innovative procedures with excellent oncological outcome, such as TMMR by the Leipzig group [29] or VALRH by the Berlin group [25] are proportionally well represented. Thus we can hope that in the years to come the monocentric data will be confirmed by multicentric results. Less easily understandable are the answers of German hospitals in $74 \%$ and $43 \%$, respectively, to continue with $\mathrm{RH}$ in the presence of positive pelvic or paraaortic lymph nodes. This could be based on the fact that $43 \%$ of the hospitals do not perform intraoperative immediate sections or on economic reasons, especially as practically all hospitals recommend an adjuvant RCTX in the presence of positive lymph nodes. The recommendation of GOG 109 study for an adjuvant therapy in cases of $\mathrm{N} 1$, parametrial infiltration and an $\mathrm{R} 1 / \mathrm{R} 2$ resection are almost unanimously implemented in German hospitals $[40,69]$. The comments of the gynaecological departments about an adjuvant therapy after RH in the presence of only one or several intermediate risk factors clearly reflect the, also internationally, much too high rate of trimodal therapy, the oncological utility of which has not yet been clarified for many combinations of these risk factors [41,42]. Marnitz et al. have impressively demonstrated that the rate of adjuvant RCTX can be minimised to $10 \%$ with the help of laparoscopic staging and with knowledge of the histological results of preoperative biopsies/conisation; in this way the significantly elevated morbidity of RH and RCTX can be avoided [39]. For this complex of topics, in particular, a revised German guideline with clear unambiguous statements is needed.

The optimal therapy for patients in FIGO stages IB2 and IIB has been a subject of controversial discussion for many years, but is still not clear as is reflected in the results of this and earlier questionnaires [98]. The spectrum of nationally as well as internationally applied therapies encompasses primary radical hysterectomy \pm adjuvant radiochemotherapy, neoadjuvant (radio)chemotherapy followed by radical hysterectomy, primary radiochemotherapy (RCTX) or TMMR. In the not yet closed prospective randomised international EORTC study 55994, neoadjuvant chemotherapy followed by radical hysterectomy is being compared with primary RCTX in the tumour stages IB2-IIB. A randomised study to compare the primary operation followed by adjuvant RCTX with primary RCTX for these tumour stages has not yet been undertaken. In non-randomised studies that have compared various therapeutic procedures, both significant and nonsignificant differences have been presented [70-77].

Whereas in the last century, an operation for patients with cervical cancers up to stage IIB was in most cases the therapy of choice, in the present century primary radiochemotherapy has become established worldwide for patients in FIGO stage IIB on the basis of the results of 5 prospective randomised studies. The significant improvement in survival (referred to OS) in favour of combined radiochemotherapy as compared to radiation alone has been proven in several metaanalyses. For patients in stage IIB the improvement in survival amounts to $7 \%$ [33], or in a large retrospective analysis by Beck et al. on the basis of data for 5476 patients even to $13 \%$ [34]. The result of the questionnaire with regard to therapy in stage IIB with a rate of $46 \%$ for RH as primary therapy is thus surprising.

For patients with a cervical cancer in stage IVA individual therapeutic decisions should be made because there are no randomised comparisons between primary exenteration and primary
RCTX, this opinion is shared by $82 \%$ of the German hospitals. The question why only $13 \%$ of the hospitals prefer a primary exenteration in cases of pre-existing fistula formation must be evaluated critically with regard to the available surgical expertise in Germany [78-80].

The follow-up of patients after primary therapy for cervical cancer, especially primary RCTX, is regulated with regard to time intervals but not with regard to extent. Also in Germany the clinical examination with vaginal ultrasonography is used routinely even when its utility with regard to detection of local recurrence/progression is limited. Thus, according to Duyn et al. only $32 \%$ of the recurrences are detected in the follow-up [81], or according to Ansink et al. merely 26\% [82]. Imaging procedures such as CT or MRI or PAP smears are, however, not superior to the clinical examination [83]. The utility of MRI in the follow-up is also disputed, as described by Balleyguier et al.[84], accordingly the moderate use in $41 \%$ of the hospitals is justified. PET-CT is associated with a high rate of false negative and false positive findings in the diagnosis of recurrences as has been demonstrated by Chung et al. in 276 patients [85], whereas in other studies it has revealed a good correlation between complete metabolic response and survival [86]. Further studies on the value of PET-CT in the follow-up are needed. The determination of the tumour markers SCC and CEA is undertaken in $28 \%$ of the German hospitals $[46,87]$, even when the available data suggest that the determination of these markers is not reliable $[46,87]$.

Routinely taken cytological samples - as is done in $75 \%$ of the gynaecological departments - should no longer be considered as the sole follow-up examination on account of the low detection rate for recurrences of between 0 and 17\% [88-91,97]. According to Nijhuis et al. the combination of examinations under anaesthesia with biopsy sampling/cervical abrasion can detect or exclude a local persisting tumour after primary RCTX with a high probability [91]. This method should thus be employed more often than its current implementation in merely $28 \%$ of the hospitals. The wide spectrum of answers with regard to secondary operation in patients after primary RCTX for cervical cancer reflects the lack of evidence on this topic. While Motton et al. did not observe any increased rate of complications, Classe et al. and Colombo et al. recorded complications in $26-48 \%$ of their secondary operations. To what extent a simple hysterectomy is oncologically more meaningful than a radical hysterectomy or an exenteration also remains to be clarified. None of the studies could show any advantages with regard to overall survival, merely local control or, respectively, PFS were improved [91-97]. A randomised study of surgical strategies for persisting tumours is ethically not possible.

Of course, the results presented here have their limitations. The design and length of the questionnaire did not allow the inclusion of all interesting questions and all possible answers. Also the fact that only a good third of the hospitals responded means that the results are still representative, although a higher participation would have been highly desirable.

\section{Conclusion \\ $\nabla$}

The results of this questionnaire on the therapy for cervical cancer in Germany in 2012 reveal on the one hand that innovative concepts (laparoscopic procedures for RH, TMMR, surgical staging) have found acceptance in German hospitals while, on the other hand, long established treatment concepts ( $\mathrm{RH}$ in case of 
positive pelvic and/or paraaortic lymph nodes, therapy in FIGO stage IIB, recommendation for adjuvant therapy) are being retained. Randomised prospective studies should be put into practice. The lack of evidence for many questions leaves room for a broad spectrum of opinions and treatment pathways. The future new version of the S3 guidelines on the diagnostics and therapy for patients with cervical cancer should thus include unambiguous statements for many of these aspects.

\section{Acknowledgements}

The authors are extremely grateful to all colleagues who returned the questionnaires and provided helpful suggestions and support.

\section{Conflicts of Interest}

$\nabla$

None.

\section{References}

1 S2-Leitlinie zur Diagnostik und Therapie des Zervixkarzinoms der Kommission Uterus der AGO vom 07.12.2006, Überarbeitung 2008. www.ago-online.de

2 www.NCCN.org; last access: 01/2013

3 Querleu D, Morrow CP. Classification of radical hysterectomy. Lancet Oncol 2008; 9: 297-303

4 Cibula D, Abu-Rustum NR, Benedetti-Panici P et al. New classification system of radical hysterectomy: emphasis on a three dimensional anatomic template for parametrial resection. Gynecol Oncol 2011; 122: 264-268

5 Robert Koch-Institut; Gesellschaft der epidemiologischen Krebsregister in Deutschland e.V., Ed. Krebs in Deutschland 2007/2008. 8th edn. Berlin: 2012

6 Mitchell DG, Snyder B, Coakley F et al. Early invasive cervical cancer: MRI and CT predictors of lymphatic metastases in the ACRIN 6651/ GOG 183 intergroup study. Gynecol Oncol 2009; 112: 95-103

7 Ramirez PT, Jhingran A, Macapinlac HA et al. Laparoscopic extraperitoneal para-aortic lymphadenectomy in locally advanced cervical cancer: a prospective correlation of surgical findings with positron emission tomography/computed tomography findings. Cancer 2011; 117: 1928-1934

8 Leblanc E, Gauthier H, Querleu D et al. Accuracy of 18-fluoro-2-deoxyD-glucose positron emission tomography in the pretherapeutic detection of occult para-aortic node involvement in patients with a locally advanced cervical carcinoma. Ann Surg Oncol 2011; 18: 2302-2309

9 Monteil J, Maubon A, Leobon $S$ et al. Lymph node assessment with (18)F-FDG-PET and MRI in uterine cervical cancer. Anticancer Res 2011; 31: 3865-3871

10 Gouy S, Morice P, Narducci F et al. Nodal-staging surgery for locally advanced cervical cancer in the era of PET. Lancet Oncol 2012; 13: e212e220

11 Fagotti A, Fanfani F, Longo R et al. Which role for pre-treatment laparoscopic staging? Gynecol Oncol 2007; 107 (1 Suppl. 1): S101-S105

12 Marnitz S, Köhler C, Roth C et al. Is there a benefit of pre-treatment laparoscopic transperitoneal surgical staging in patients with advanced cervical cancer? Gynecol Oncol 2005; 99: 536-544

13 Lai CH, Huang KG, Hong JH et al. Randomized trial of surgical staging (extraperitoneal or laparoscopic) versus clinical staging in locally advanced cervical cancer. Gynecol Oncol 2003; 89: 160-167

14 Altgassen C, Hertel H, Brandstädt A et al.; AGO study group. Multicenter validation study of the sentinel lymph node concept in cervical cancer. J Clin Oncol 2008; 26: 2943-2951

15 Lanowska M, Morawietz L, Sikora A et al. Prevalence of lymph nodes in the parametrium of radical vaginal trachelectomy (RVT) specimen. Gynecol Oncol 2011; 121: 298-302

16 Lee CL, Huang KG, Wang CJ et al. Laparoscopic radical hysterectomy using pulsed bipolar system: comparison with conventional bipolar electrosurgery. Gynecol Oncol 2007; 105: 620-624
17 Pellegrino A, Vizza E, Fruscio R et al. Total laparoscopic radical hysterectomy and pelvic lymphadenectomy in patients with stage Ib1 cervical cancer: analysis of surgical and oncologic outcome. Eur J Surg Oncol 2009; 35: 98-103

18 Liang Z, Chen $Y, X u H$ et al. Laparoscopic nerve-sparing radical hysterectomy with fascia space dissection technique for cervical cancer: description of technique and outcomes. Gynecol Oncol 2010; 119: 202207

19 Yan X, Li G, Shang $H$ et al. Twelve-year experience with laparoscopic radical hysterectomy and pelvic lymphadenectomy in cervical cancer. Gynecol Oncol 2011; 120: 362-367

20 Hong JH, Choi JS, Lee JH et al. Comparison of survival and adverse events between women with stage IB1 and IB2 cervical cancer treated by laparoscopic radical vaginal hysterectomy. Ann Surg Oncol 2012; 19: 605-611

21 Hertel $\mathrm{H}$, Köhler C, Michels Wet al. Laparoscopic-assisted radical vaginal hysterectomy (LARVH): prospective evaluation of 200 patients with cervical cancer. Gynecol Oncol 2003; 90: 505-511

$22 \mathrm{Nam} \mathrm{JH}$, Kim JH, Kim DY et al. Comparative study of laparoscopico-vaginal radical hysterectomy and abdominal radical hysterectomy in patients with early cervical cancer. Gynecol Oncol 2004; 92: 277-283

23 Steed H, Rosen B, Murphy J et al. A comparison of laparoscopic-assisted radical vaginal hysterectomy and radical abdominal hysterectomy in the treatment of cervical cancer. Gynecol Oncol 2004; 92: 588-593

24 Mehra G, Weekes A, Vantrappen P et al. Laparoscopic assisted radical vaginal hysterectomy for cervical carcinoma: morbidity and long-term follow-up. Eur J Surg Oncol 2010; 36: 304-308

25 Koehler C, Gottschalk E, Chiantera V et al. From laparoscopic assisted radical vaginal hysterectomy (LARVH) to vaginal assisted laparoscopic radical hysterectomy (VALRH). BJOG 2012; 119: 254-262

26 Persson J, Revnisson P, Borgfeldt C et al. Robot assisted laparoscopic radical hysterectomy and pelvic lymphadenectomy with short and long term morbidity data. Gynecol Oncol 2009; 113: 185-190

27 Cantrell LA, Mandivil A, Gehrig PA et al. Survival outcomes for women undergoing type III robotic radical hysterectomy for cervical cancer: a 3-year experience. Gynecol Oncol 2010; 117: 260-265

28 Geetha P, Nair MK. Laparoscopic, robotic and open method of radical hysterectomy for cervical cancer: A systematic review. J Minim Access Surg 2012; 8: 67-73

29 Höckel M, Horn LC, Tetsch E et al. Pattern analysis of regional spread and therapeutic lymph node dissection in cervical cancer based on ontogenetic anatomy. Gynecol Oncol 2012; 125: 168-174

30 Rose PG, Bundy BN, Watkins EB et al. Concurrent cisplatin-based radiotherapy and chemotherapy for locally advanced cervical cancer. N Engl J Med 1999; 340: 1144-1153; Erratum in: N Engl J Med 1999; 341: 708

31 Whitney CW, Sause W, Bundy BN et al. Randomized comparison of fluorouracil plus cisplatin versus hydroxyurea as an adjunct to radiation therapy in stage IIB-IVA carcinoma of the cervix with negative paraaortic lymph nodes: a Gynecologic Oncology Group and Southwest Oncology Group study. J Clin Oncol 1999; 17: 1339-1348

32 Pearcey R, Brundage M, Drouin P et al. Phase III trial comparing radical radiotherapy with and without cisplatin chemotherapy in patients with advanced squamous cell cancer of the cervix. J Clin Oncol 2002; 20: 966-972

33 Chemoradiotherapy for Cervical Cancer Meta-Analysis Collaboration. Reducing uncertainties about the effects of chemoradiotherapy for cervical cancer: a systematic review and meta-analysis of individual patient data from 18 randomized trials. J Clin Oncol 2008; 26: 5802-5812

34 Beck T, Sukumvanich P, Rubatt J et al. Impact of the National Cancer Institute's clinical announcement on cervical cancer survival. Gyn Oncol 2010; 116 (Suppl. 1): S2-S169

35 Marnitz S, Köhler C, Burova E et al. Helical tomotherapy with simultaneous integrated boost after laparoscopic staging in patients with cervical cancer: analysis of feasibility and early toxicity. Int J Radiation Oncology Biol Phys 2012; 82: e137-e143

36 Marnitz S, Lukarski D, Köhler C et al. Helical tomotherapy versus conventional intensity-modulated radiation therapy for primary chemoradiation in cervical cancer patients: an intraindividual comparison. Int J Radiation Oncology Biol Phys 2011; 81: 424-430

37 Landoni F, Maneo A, Colombo A et al. Randomised study of radical surgery versus radiotherapy for stage IB-II a cervical cancer. Lancet 1997; 350: $535-540$ 
38 Yamashita H, Okuma K, Kawana K et al. Comparison between conventional surgery plus postoperative adjuvant radiotherapy and concurrent chemoradiation for FIGO stage IIB cervical carcinoma: a retrospective study. Am J Clin Oncol 2010; 33: 583-586

39 Marnitz S, Köhler C, Affonso RJ et al. Validity of laparoscopic staging to avoid adjuvant chemoradiation following radical surgery in patients with early cervical cancer. Oncology-Basel 2012; 18: 346-353

40 Van de Putte G, Lie AK, Vach Wet al. Risk grouping in stage IB squamous cell cervical carcinoma. Gynecol Oncol 2005; 99: 106-112

41 Delgado G, Bundy B, Zaino $R$ et al. Prospective surgical-pathological study of disease-free interval in patients with stage IB squamous cell carcinoma of the cervix: a Gynecologic Oncology Group study. Gynecol Oncol 1990; 38: 352-357

42 Ryu SY, Park SI, Nam BH et al. Is adjuvant chemoradiotherapy overtreatment in cervical cancer patients with intermediate risk factors? Int J Radiat Oncol Biol Phys 2011; 79: 794-799

43 Sartori E, Tisi G, Chiudinelli $F$ et al. Early stage cervical cancer: adjuvant treatment in negative lymph node cases. Gynecol Oncol 2007; 107: S170-S174

44 Morice P, Deyrolle C, Rey A et al. Value of routine follow-up procedures for patients with stage I/II cervical cancer treated with combined surgery - radiation therapy. Ann Oncol 2004; 15: 218-223

45 Bodurka-Bevers D, Morris M, Eifel PJ et al. Posttherapy surveillance of women with cervical cancer: an outcomes analysis. Gynecol Oncol 2000; 78: 187-193

46 Chan YM, Ng TY, Ngan HY et al. Monitoring of serum squamous cell carcinoma antigen levels in invasive cervical cancer: is it cost-effective? Gynecol Oncol 2002; 84: 7-11

47 Lindsay $R$, Paul J, Siddiqui $N$ et al. Survey on the management of early cervical cancer among members of the GCIG. Int J Gynecol Cancer. 2012; 22: 1617-1623

48 Stang A, Merrill RM, Kuss O. Hysterectomy in Germany: a DRG-based nationwide analysis 2005-2006. Dtsch Arztebl Int 2011; 108: 508-514

49 Porcorelli $S$. 26th annual report on the results of treatment in gynecologic cancer. Int J Gynecol Oncol 2006; 95 (Suppl. 1): S43-S108

50 Hertel H, Köhler C, El-Hawary T et al. Laparoscopic staging compared with imaging techniques in the staging of advanced cervical cancer. Gynecol Oncol 2002; 87: 46-51

51 Mitchell DG, Snyder B, Coakley $F$ et al. Early invasive cervical cancer: MRI and CT predictors of lymphatic metastases in the ACRIN 6651/ GOG 183 intergroup study. Gynecol Oncol 2009; 112: 95-103

52 Bleker SM, Bipat S, Spijkerboer AM et al. The negative predictive value of clinical examination with or without anesthesia versus magnetic resonance imaging for parametrial infiltration in cervical cancer stages IB1 to IIA. Int J Gynecol Cancer 2013; 23: 193-198

53 Epstein E, Testa A, Gaurilcikas A et al. Early-stage cervical cancer: tumor delineation by magnetic resonance imaging and ultrasound - A European multicenter trial. Gynecol Oncol 2013; 128: 449-453

54 Klerkx WM, Veldhuis WB, Spijkerboer AM et al. The value of 3.0 Tesla diffusion-weighted MRI for pelvic nodal staging in patients with early stage cervical cancer. Eur J Cancer 2012; 48: 3414-3421

55 Monteil J, Maubon A, Leobon $S$ et al. Lymph node assessment with (18)F-FDG-PET and MRI in uterine cervical cancer. Anticancer Res 2011; 31: 3865-3871

56 Gold MA, Tian C, Whitney CW et al. Surgical versus radiographic determination of para-aortic lymph node metastases before chemoradiation for locally advanced cervical carcinoma: a Gynecologic Oncology Group Study. Cancer 2008; 112: 1954-1963

57 Denschlag D, Gabriel B, Mueller-Lantzsch C et al. Evaluation of patients after extraperitoneal lymph node dissection for cervical cancer. Gynecol Oncol 2005; 96: 658-664

58 Lécuru F, Mathevet P, Querleu D et al. Bilateral negative sentinel nodes accurately predict absence of lymph node metastasis in early cervical cancer: results of the SENTICOL study. J Clin Oncol 2011; 29: 16861691

59 Greggi S, Scaffa C. Surgical management of early cervical cancer: the shape of future studies. Curr Oncol Rep 2012; 14: 527-534

60 Bats AS, Mathevet P, Buenerd A et al. The Sentinel Node Technique Detects Unexpected Drainage Pathways and Allows Nodal Ultrastaging in Early Cervical Cancer: Insights from the Multicenter Prospective SENTICOL Study. Ann Surg Oncol 2013; 20: 413-422

61 Cibula D, Abu-Rustum NR, Dusek L et al. Bilateral ultrastaging of sentinel lymph node in cervical cancer: Lowering the false-negative rate and improving the detection of micrometastasis. Gynecol Oncol 2012; 127: 462-466
$62 \mathrm{Nam}$ JH, Kim SH, Kim JH et al. Nonradical treatment is as effective as radical surgery in the management of cervical cancer stage IA1. Int J Gynecol Cancer 2002; 12: 480-484

63 Argenta PA, Kubicek GJ, Dusenberry KE et al. Widespread lymph node metastases in a young woman with FIGO stage IA1 squamous cervical cancer. Gynecol Oncol 2005; 97: 659-661

64 Dedes KJ, Dedes M, Varga Z et al. Curative treatment of a pelvic side wall recurrence after conization for microinvasive cervical cancer stage IA1: a case report and review of the literature. J Low Genit Tract Dis 2007; 11: $177-181$

65 Diaz JP, Gemignani ML, Pandit-Taskar N et al. Sentinel lymph node biopsy in the management of early-stage cervical carcinoma. Gynecol Oncol 2011; 120: 347-352

66 Lanowska M, Mangler M, Spek A et al. Radical vaginal trachelectomy (RVT) combined with laparoscopic lymphadenectomy: prospective study of 225 patients with early-stage cervical cancer. Int J Gynecol Cancer 2011; 21: 1458-1464

67 Speiser D, Mangler M, Köhler C et al. Fertility outcome after radical vaginal trachelectomy: a prospective study of 212 patients. Int J Gynecol Cancer 2011; 21: 1635-1639

68 Mangler M, Speiser D, Nguyen BD et al. Neonatal outcome in infants of patients with radical vaginal trachelectomy. J Perinat Med 2012; 40: 503-509

69 Peters WA 3rd, Liu PY, Barrett RJ 2nd et al. Concurrent chemotherapy and pelvic radiation therapy compared with pelvic radiation therapy alone as adjuvant therapy after radical surgery in high-risk early stage cancer of the cervix. Clin Oncol 2000; 18: 1606-1613

70 Cho YH, Kim DJ, Kim JH et al. Comparative study of neoadjuvant chemotherapy before radical hysterectomy and radical surgery alone in stage IB2-IIA bulky cervical cancer. J Gynecol Oncol 2009; 20: 22-27

71 Wen $\mathrm{H}, \mathrm{Wu} \mathrm{X}, \mathrm{Li} \mathrm{Z}$ et al. A prospective randomised controlled study on multiple neoadjuvant treatment for patients with stage IB2-IIA cervical cancer. Int J Gynecol Cancer 2012; 22: 296-302

72 Benedetti-Panici P, Greggi S, Colombo A et al. Neoadjuvant chemotherapy and radical surgery versus exclusive radiotherapy in locally advanced squamous cell cervical cancer: results from the Italian multicentre randomized study. J Clin Oncol 2001; 20: 179-188

73 Yin M, Zhao F, Lou G et al. The long-term efficacy of neoadjuvant chemotherapy followed by radical hysterectomy compared with radical surgery alone or concurrent chemoradiotherapy on locally advancedstage cervical cancer. Int J Gynecol Cancer 2011; 21: 92-99

74 Gong L, Lou JY, Wang P et al. Clinical evaluation of neoadjuvant chemotherapy followed by radical surgery in the management of stage IB2IIB cervical cancer. Int J Gynaecol Obstet 2012; 117: 23-26

75 Lee JY, Kim YH, Kim MJ et al. Treatment of stage IB2, IIA bulky cervical cancer: a single-institution experience of neoadjuvant chemotherapy followed by radical hysterectomy and primary radical hysterectomy. Arch Gynecol Obstet 2011; 284: 477-482

76 Ryu HS, Kang SB, Kim KT et al. Efficacy of different types of treatment in FIGO stage IB2 cervical cancer in Korea: results of a multicenter retrospective Korean study (KGOG-1005). Int J Gynecol Cancer 2007; 17: $132-136$

77 Eddy GL, Bundy BN, Creasman WT et al. Treatment of ("bulky") stage IB cervical cancer with or without neoadjuvant vincristine and cisplatin prior to radical hysterectomy and pelvic/para-aortic lymphadenectomy: a phase III trial of the gynecologic oncology group. Gynecol Oncol 2007; 106: 362-369

78 Schmidt AM, Imesch P, Fink $D$ et al. Indications and long-term clinical outcomes in 282 patients with pelvic exenteration for advanced or recurrent cervical cancer. Gynecol Oncol 2012; 125: 604-609

79 Marnitz S, Köhler C, Müller M et al. Indications for primary and secondary exenterations in patients with cervical cancer. Gynecol Oncol 2006; 103: $1023-1030$

80 Forner DM, Lampe B. Exenteration as a primary treatment for locally advanced cervical cancer: long-term results and prognostic factors. Am J Obstet Gynecol 2011; 205: 148.e1-148.e6

81 Duyn A, Van Eijkeren M, Kenter G et al. Recurrence cervical cancer: detection and prognosis. Acta Obstet Gynecol Scand 2002; 81: 351-355

82 Ansink A, de Barros Lopes A, Naik R et al. Recurrent stage IB cervical carcinoma: evaluation of the effectiveness of routine follow-up surveillance. Br J Obstet Gynaecol 1996; 103: 1156-1158

83 Bodurka-Bevers D, Morris M, Eifel PJ et al. Posttherapy surveillance of women with cervical cancer: an outcome analysis. Gynecol Oncol 2000; 78: 187-193 
84 Balleyguir C, Sala E, DaCunha T et al. Staging of uterine cervical cancer with MRI: guidelines of the European Society of Urogenital Radiology. Eur Radiol 2011; 21: 1102-1110

85 Chung HH, Kim JW, Kang KW et al. Predictive role of post-treatment [18F]FDG PET/CT in patients with uterine cervical cancer Eur J Radiol 2012; 81: e817-e822

86 Siva S, Herschtal A, Thomas JM et al. Impact of post-therapy positron emission tomography on prognostic stratification and surveillance after chemoradiotherapy for cervical cancer. Cancer 2011; 117: 39813988

87 Esajas MD, DukJM, de Bruijn HWA et al. Clinical value of routine serum squamous cell carcinoma antigen in follow-up of patients with earlystage cervical cancer. J Clin Oncol 2001; 19: 3960-3966

88 Rimel BJ, Ferda A, Erwin J et al. Cervicovaginal cytology in the detection of recurrence after cervical cancer treatment. Obstet Gynecol 2011; 118: $548-553$

89 Elit L, Fyles AW, Devries MC et al.; Gynecology Cancer Disease Site Group. Follow-up for women after treatment for cervical cancer: a systematic review. Gynecol Oncol 2009; 114: 528-535

90 Zanagnolo V, Minig LA, Gadducci A et al. Surveillance procedures for patients for cervical carcinoma. A review of the literature. Int J Gynecol Cancer 2009; 19: 306Y313

91 Nijhuis ER, van der Zee AG, in 't Hout BA et al. Gynecologic examination and cervical biopsies after (chemo) radiation for cervical cancer to identify patients eligible for salvage surgery. Int J Radiat Oncol Biol Phys 2006; 66: 699-705

92 Classe JM, Rauch P, Rodier JF et al. Surgery after concurrent chemoradiotherapy and brachytherapy for the treatment of advanced cervical cancer: Morbidity and outcome: Results of a multicenter study of the GCCLCC (Groupe des Chirurgiens de Centre de Lutte Contre le Cancer). Gynecol Oncol 2006; 102: 523-529
93 Motton S, Houvenaeghel G, Delannes $M$ et al. Results of surgery after concurrent chemoradiotherapy in advanced cervical cancer: comparison of extended hysterectomy and extrafascial hysterectomy. Int J Gynecol Cancer 2010; 20: 268-275

94 Fanfani F, Fagotti A, Ferrandina G et al. Neoadjuvant chemoradiation followed by radical hysterectomy in FIGO Stage IIIB cervical cancer: feasibility, complications, and clinical outcome. Int J Gynecol Cancer 2009; 19: 1119-1124

95 Colombo PE, Bertrand MM, Gutowski M et al. Total laparoscopic radical hysterectomy for locally advanced cervical carcinoma (stages IIB, IIA and bulky stages IB) after concurrent chemoradiation therapy: surgical morbidity and oncological results. Gynecol Oncol 2009; 114: 404409

96 Morice P, Rouanet P, Rey A et al. Results of the GYNECO 02 study, an FNCLCC phase III trial comparing hysterectomy with no hysterectomy in patients with a (clinical and radiological) complete response after chemoradiation therapy for stage IB2 or II cervical cancer. Oncologist 2012; 17: 64-71

97 Ikenberg $H$. Kontroversen um die Prävention des Zervixkarzinoms. Gebärmutterhalskrebs: Hat die Zytologie noch eine Chance? Geburtsh Frauenheilk 2012; 72: 691-693

98 Ackermann S, Beckmann M. Korreliert die Therapie des Zervixkarzinoms mit den S2-Leitlinienempfehlungen? Eine Untersuchung der Organkommission Uterusmalignome der AGO e.V. Geburtsh Frauenheilk 2005; 65: 164-171

99 Vercellino GF, Chiantera V, Gaßmann J et al. Prospective comparison of loop excision under colposcopic guidance versus Vitom guidance. Geburtsh Frauenheilk 2012; 72: 945-948

100 Ziemke P. Predictive value of class III D cytological diagnosis (Munich II, low and moderate dysplasia) and additional high-risk HPV testing. Geburtsh Frauenheilk 2012; 72: 622-629

101 Jentschke M, Soergel P, Hillemanns P. Importance of HPV genotyping for the screening, therapy and management of cervical neoplasias. Geburtsh Frauenheilk 2012; 72: 507-512

Deutschsprachige Zusatzinformationen online abrufbar unter: www.thieme-connect.de/ejournals/toc/gebfra. 